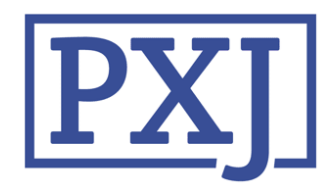

Patient Experience Journal

Volume 5

Issue 2 Patient \& Family Experience in

Children's Hospitals and Pediatric Care

Article 12

2018

\title{
Integrating the patient and caregiver voice in the context of pediatric, adolescent, and young adult care: A family-centered approach
}

\author{
Sarah K. Featherston \\ The University of Texas MD Anderson \\ Beatriz N. Rozo \\ The University of Texas MD Anderson Cancer Center \\ Danielle A. Buzanga \\ The University of Texas MD Anderson Cancer Center \\ Alexandra M. Garcia \\ The University of Texas MD Anderson Cancer Center \\ Joanne Greene \\ The University of Texas MD Anderson Cancer Center
}

See next page for additional authors

Follow this and additional works at: https://pxjournal.org/journal

Part of the Other Nursing Commons, and the Pediatric Nursing Commons

\section{Recommended Citation}

Featherston SK, Rozo BN, Buzanga DA, Garcia AM, Greene J, Salvador LK, O'Hanlon-Curry J. Integrating the patient and caregiver voice in the context of pediatric, adolescent, and young adult care: A familycentered approach. Patient Experience Journal. 2018; 5(2):91-96. doi: 10.35680/2372-0247.1294.

This Case Study is brought to you for free and open access by Patient Experience Journal. It has been accepted for inclusion in Patient Experience Journal by an authorized editor of Patient Experience Journal. 
Integrating the patient and caregiver voice in the context of pediatric, adolescent, and young adult care: A family-centered approach

\section{Cover Page Footnote}

The authors wish to acknowledge council members Allison Rosen, Jennifer Robinson, and Tammy Sharp, for their contributions to this article.

\section{Authors}

Sarah K. Featherston, Beatriz N. Rozo, Danielle A. Buzanga, Alexandra M. Garcia, Joanne Greene, Laura K. Salvador, and Joan O'Hanlon-Curry 


\author{
Integrating the patient and caregiver voice in the context of pediatric, \\ adolescent, and young adult care: A family-centered approach \\ Sarah K. Featherston, The University of Texas MD Anderson CancerCenter, skfeatherston@mdanderson.org \\ Beatriz N. Rozo, The University of Texas MD Anderson CancerCenter,brozo@mdanderson.org \\ Danielle A. Buzanga, The University of Texas MD Anderson Cancer Center, dabuzanga@mdanderson.org \\ Alexandra M. Garcia, The University of Texas MD Anderson CancerCenter, amgarcia2@mdanderson.org \\ Joanne Greene, The University of Texas MD Anderson Cancer Center, jgreene@mdanderson.org \\ Laura Salvador, The University of Texas MD Anderson Cancer Center, LEKaye@mdanderson.org \\ Joan O'Hanlon Curry, The University of Texas MD Anderson CancerCenter, JOCurry@mdanderson.org
}

\begin{abstract}
Family-centered care (FCC) is defined as an approach to care coordination founded in collaborative partnerships between healthcare providers, patients and their family caregivers. Amid the enthusiasm for FCC in the pediatric setting, opportunities have been identified to operationalize the engagement of pediatric, adolescent and young adult patients and their caregivers into decision making that translates not only to their healthcare, but also to the context in which care is provided, as well as the research informing their care. At a National Cancer Institute-designated comprehensive cancer center, the Children's Cancer Hospital was instrumental in designing and implementing patient and family engagement councils to inform institutional policies, guidelines, environment of care and research. The councils include: he Family Advisory Council, the Supportive Care Council, the Young Adult Advisory Council, and the Patient Advisory Council for Teens (imPACT). The development and outcomes of these councils is presented as an exemplar for patient and family engagement that translates to tangible healthcare delivery initiatives.
\end{abstract}

\title{
Keywords
}

Pediatrics, adolescents, young adults, cancer, family-centered care, patient engagement, family engagement

\section{Introduction}

Family-centered care (FCC) is defined as an approach to care coordination founded in collaborative partnerships between healthcare providers, patients and their family caregivers (caregivers). ${ }^{1} \mathrm{FCC}$ incorporates both care coordination, which includes a holistic approach to the physical, psychosocial, and emotional needs of the patient ${ }^{2}$, and the engagement of the patient and caregiver dyad to inform, design and improve health services. ${ }^{3}$ The focus on both patient and caregiver engagement emerges from a 2012 Institute of Medicine publication that emphasizes not only the importance of engagement, but the value of resulting outcomes, which include benefits to both healthcare systems, such as decreased utilization of resources, and to patients, such as reduced pain and discomfort and increased adherence to treatment. ${ }^{4}$

In a scoping review of the literature on patient and family engagement ${ }^{3}$, the authors identify the International Association for Public Participation (IAP2) model as a template for the types of potential engagement between patients, their caregivers and the healthcare system. ${ }^{5}$ Patient family advisory councils (PFACs) are a wellestablished method of engaging patients to share personal experiences and collaborate with hospital staff and administrators on various patient-focused initiatives, and have been implemented across diverse healthcare settings, including cancer centers ${ }^{6}$ and primary care settings. ${ }^{7}$ PFACs have been introduced to enhance pediatric care in the emergency ${ }^{8}$ and hospital settings. ${ }^{9}$ PFACs have been associated with improved outcomes, including reducing patient falls, enhancing patient-provider communication, assisting in facilities design, and improving billing processes. ${ }^{10}$

Despite their increasing prevalence, most PFACs share a similar format that focuses on one primary council engaged in similar activities of informing hospital policies, space, and procedures. Few if any councils are reported in the literature that discuss councils designed based on the unique developmental stages of participants, nor with particular focus points such as supportive care. A spectrum of autonomy for engagement must be considered when determining the balance of engagement of pediatric patients across developmental trajectories. While parental caregivers may have higher engagement and greater autonomy in decision making when caring for young children, adolescents and young adults have the potential for enhanced desire for and engagement in 
autonomous decision making about their care. Studies suggest that teenage patients appreciate the value of and engagement in collaboration with providers around both their healthcare and research, providing the opportunity for participation that is meaningful and has potential for lasting impact on research development and care delivery. ${ }^{11}$ Given the evidence of the potential benefits of patient-family engagement for both the individuals and the respective healthcare systems with which they interact, the need for purposeful engagement structure is imperative.

This article presents a specialized template for engaging PFAC participants according to age, as well as aligned to distinct focal points. While PFACs are well established in the literature, the modification of a PFAC format to specifically engage adolescents and young adults, as well as to focus on supportive care, is novel and unique to this institution. The design, membership and outcomes of these councils are presented, along with implications for practice in other pediatric care settings.

\section{The Development of a Councilar Structure in a Children's Cancer Hospital}

The Children's Cancer Hospital (CCH) at a National Cancer Institute-designated comprehensive cancer center identified an opportunity to engage patients and caregivers across the spectrum of pediatric care through the development of councils aimed at interprofessional patient-caregiver- provider collaboration to inform and improve care delivery within this institution. The $\mathrm{CCH}$, which consists of both inpatient and ambulatory services for patients from birth to age 25 , adopted family-centered care as the framework for patient and caregiver engagement in holistic care delivery in 2008. In developing the councils within the $\mathrm{CCH}$ the planning committee utilized the IAP2 model $^{5}$ to inform the conceptual framework and design for the councils. The IAP2 model highlights engagement in 5 stages: informing, consulting, involving, collaborating, and empowering. ${ }^{5}$ Each stage has a growing level of autonomous engagement for participants, and provides a framework to guide patient and caregiver engagement in the clinical setting. The advisory councils naturally aligned to the family-centered care framework, encouraging participants to be fully engaged at all levels of healthcare decision making, including individual care decisions, health system learning, and interventions to promote health. ${ }^{4}$

Council structure and membership were the result of a reflective process by the initial planning committee who emphasized an intentional commitment to have a multicouncil structure that could engage patients at various stages of development, as well as a distinct council to focus on supportive care needs of patients. Four councils were formed to encourage and support patient and caregiver involvement: the Family Advisory Council which provides input on patient care practices and institutional changes, the Supportive Care Council to improve patient and caregiver experiences at end of life, and the Young Adult Advisory Council (YAAC) and Patient Advisory Council for Teens (imPACT) to give a voice to the teens and young adults receiving treatment during one of the most formative times of their lives. The council goals are to address needs along the complete continuum from diagnosis to survivorship or end of life, and to inform both clinical practice and the development of an agesensitive care environment in which this care is delivered. Members are engaged through each of the stages of the IAP2 model, with an emphasis on collaborating with interprofessional health care team members, and empowering patients and their caregivers to autonomously guide decision making. The councils' structure, membership and exemplars of their outcomes are presented below.

\section{Family Advisory Council}

The Family Advisory Council, most closely aligned to PFACs reported in the literature, represents the caregiver population who work collaboratively with hospital faculty and staff to support decision making for both the $\mathrm{CCH}$ and the institution. The members of the Family Advisory Council strive to continually improve the experience of care for children, adolescents, young adults and their families by embodying the collaborative philosophy of patient/family- centered care. Council members collaborate with physicians, staff, and families in developing, implementing, and evaluating policies, programs, and services and actively developing partnerships within and between pediatric and adult cancer care programs at this institution.

Membership consists of approximately 30 individuals including 12 parents/caregivers, 13 faculty/staff and 5 ad hoc members representing the Ronald McDonald House, institutional communications, and other special interest groups. Caregivers represent a diversity of patients' diagnoses, ages and stages of treatment. Faculty and staff members include physicians, nurses, advanced practice providers (nurse practitioners and physician assistants), administrators, school staff, child life specialists, translators and physical therapists.

The Family Advisory Council serves in several of the stages of the IAP 2 model. They have served as consultants for various initiatives in the organization, providing feedback and perspectives on topics including the patient facing design of the electronic health record. The Council was also involved as active participants in the redesign of the $\mathrm{CCH}$ clinical space, assisting in the choosing of décor, including mood lighting in each patient room that allows the patient to communicate to staff what mood they are in through the choice of different lighting colors. They also were asked to test different furniture 
options, providing critical feedback on what it is like to sit or sleep at a child's bedside to emphasize the need for both comfort and functionality in the furniture choices. The Council collaborated with patient education on the development of a welcome packet for patients and caregivers to provide an overview of services and what to expect during treatment in the $\mathrm{CCH}$. Council members were integral in informing the content of the document, not simply approving content provided to them, contributing to education that is designed by patients and caregivers, for patients and caregivers. This project expanded to include a parent education program that is customizable by disease type. At the level of empowerment, the Council was responsible for the identification of a need for pediatric hospital gowns that were both size and print appropriate for patients from a wide range of ages treated in the $\mathrm{CCH}$. In identifying this need the Council was empowered to lead the search and recommendations of gowns to the institution. This included meeting with vendors, identifying functionality in the gowns for different types of patient care and line access, and ensuring prints and colors that are age appropriate. This resulted in recommendations to the institution that were adopted, resulting in a contract with a vendor for the continual supply of pediatric appropriate patient gowns.

The Family Advisory Council served as the template for the development of three additional council structures to engage adolescent and young adult patients in similar decision- making models, as well as to specifically inform supportive care in the CCH. Caregiver participants note their gratitude in being able to "give back" to others who may be going through a similar caregiver experience and for the platform to help improve processes that might have proved challenging for them or for the patient.

\section{Supportive Care Council}

The Supportive Care Council is unique in that it is intentionally comprised of caregivers who have experienced the loss of a child to cancer. Though supportive (palliative) care is recommended for integration from the time of diagnosis ${ }^{12}$, barriers may remain due to lack of standardized implementation of pediatric palliative care guidelines. ${ }^{13}$ Evidence suggests that, as for adults, the introduction of palliative care for pediatric cancer patients can enhance quality of life ${ }^{14}$ and reduce costs of care at the end of life. ${ }^{15}$ As such, early and effective palliative care for pediatric patients is imperative to enhance outcomes for patients and reduce the financial burden of care. Yet studies suggest barriers remain for healthcare providers to discuss end of life care with pediatric patients and their caregivers. ${ }^{16,17}$ Similarly, opportunities were identified to enhance resources for and communication about palliative and end of life care for pediatric oncology patients at this institution.

The Supportive Care Council was designed to improve the experience of care for children, adolescents, young adults and families who require significant symptom control and who may require hospice and/or end-of-life care. The goal of the Supportive Care Council is to support the evidencebased care of patients throughout the treatment trajectory through the integration of supportive care. The Council goals include educating patients and families regarding the resources and services available for symptom management/end-of-life care, collaborating with faculty and staff to provide appropriate education and end-of-life services to patients and families and to use evidence-based medicine in collaboration with patient experience to address the needs of families and provide high quality endof-life care. Members include 8-10 parents and caregivers, all of whom experienced the death of a child after cancer treatment at this institution. Bereaved parents are eligible to join by invitation greater than one year after the patient's death. These parents represent a variety of diagnoses and end of life experiences including home hospice and hospital-based care. Also represented are faculty and staff including physicians, nurses, advanced practice providers, child life, psychology, social work and chaplaincy.

This Council has primarily engaged in empowered activities, which include major initiatives for both caregivers and providers. The caregiver members of the Council developed two educational booklets focused on palliative and end of life care for pediatric patients. The first, entitled "My Child Isn't Getting Better - a helpful guide for parents from parents," addresses how to discuss end of life with your child and family members, what to expect in relation to symptom management and the dying process and finally funeral planning and resources for dealing with the grief following the death of a child. The second, entitled "Hospice Care - a helpful guide for parents from parents," defines hospice care and its supportive resources for both the patient and their caregivers during serious illness or at the end of life.

These materials were so well received by caregivers that they have been published in both English and Spanish and demonstrate a truly family-centered approach to providing education based on the lived experience of caregivers who have experience a child's death due to cancer.

Additional resources developed in collaboration with this Council include an electronic end of life tool kit resource for faculty and staff, comfort carts and bereavement packets for families who have lost a child, and "soul kits," caring bags with snacks and words of encouragement for staff caring for patients at end of life. These resources 
have resulted in not only enhanced care for patients and caregivers, but also for the staff who care for them, emphasizing a truly integrative approach to patient care delivery in this setting.

As one caregiver member of the Council articulated, "The heart and mind of a loving parent is not wired to even consider that our children will die before we do. To even think it, feels as though we are giving up on them, and we CANNOT do that. Yet, my deepest love could not keep [my child] from the reality that she would not survive CANCER. Somehow I had to find a way to face that reality so that I could help her have control over what time she had and assure that she knew that the life she lived had meaning that would survive long after she died. [My child's] one fear was that she might be forgotten. Being a part of the Supportive Care Council has allowed me to keep my promise that she would not be forgotten and that her struggles would be used to help other kids have a voice. Our struggle is being used to help other parents navigate the most difficult time of their lives."

\section{imPACT}

imPACT (Patient Advisory Council for Teens) was formed specifically for teens at the Children's Cancer Hospital. Its members include 10-12 patients, ages 13-18 in all stages of treatment and is currently facilitated by 3 staff members, a child life specialist, an educator and a physician assistant. This Council aims at providing an opportunity for adolescent patients to partner with health professionals to provide feedback on resources and programming and improve the treatment experience for teens and their families.

imPACT has been engaged as a consult service to obtain feedback on institutional initiatives including working with the pediatric research team to develop nutrition related resources, providing feedback and ideas regarding summer camp programming, developing pediatric hospital gowns and participating in school improvement plan surveys for school accreditation. Council members have also been engaged in a collaborative capacity to assist with interviewing and hiring new staff for the $\mathrm{CCH}$. They meet as a group with the potential candidate and provide feedback that is considered when choosing support staff, including child life specialists and school teachers.

Council members are also empowered through their engagement with $\mathrm{CCH}$ prom planning committee. They contribute to the design and preparation for the annual prom event that includes activities for all ages and has become extremely popular among patients, families and care teams. Council members also serve as volunteers to provide an evening of fun, normalization and distraction for teen patients undergoing treatment and in survivorship. An additional empowered activity is the development of a comic book series detailing five important areas of the cancer journey: Diagnosis, Treatment, Remission, Relapse and Survivorship. Each book chronicles the cancer experience through the eyes of a teenager. These books include thoughts, questions, fears, experiences and personal stories with the hope of providing support and guidance for future patients. The books were created after a need was identified as something they felt would have been helpful not only to them as patients but also for the support system around them including friends, family members, medical professionals and others in their community. These creative books are poignant, raw and truthful

representations of the cancer journey, reflecting the unique needs and insights of adolescents with cancer. ${ }^{18,19}$

\section{Young Adult Advisory Council}

The CCH serves a large age, range, generally up to 25 years of age. Those over 18 were either diagnosed as a child, relapsed and prefer to stay with their original pediatric oncologist for continuity of care. Additionally, individuals in this age group who are newly diagnosed with types of cancer most often found in a pediatric population (e.g. Wilms Tumor or neuroblastoma) are also treated in the $\mathrm{CCH}$. In addition, the young adult "Y" service provides medical and psychosocial management for young adults up to age 25 undergoing stem cell transplantation.

The Young Adult Advisory Council was implemented in 2009 to allow young adults a distinct space to voice their preferences for care. This is particularly important given the unique developmental needs of young adults that distinguish them from adolescents and older adults with cancer. The Council has evolved to include 24 members, 12 staff and 12 patients. Its purpose is to allow for better communication and collaboration with a goal of greater focus on the needs of young adults during and after their cancer treatment. Within the Council are subcommittees which include Institutional outreach, publications, events, development and community outreach. These

committees, formed in 2014, specifically target young adult activities and give these patients a platform to voice their concerns and be part of significant changes within the institution. The Council has served as a consult body for various young adult research studies and resource support development. In addition, they were involved in providing feedback for the redesign of a social space for adolescents and young adults treated in this hospital. They collaborated with researchers to inform the development of a survey instrument for use in a grant application. The Council has been empowered in its development of an educational guide for young adults entitled "10 things every young adult should know during cancer care", a series of vignette driven resources on common topics of interest to young adults with cancer including fertility, intimacy during and after treatment, insurance, working through or after 
treatment, and remaining in or returning to school after treatment.

Most recently the Council was involved in the planning and development of an Adolescent Young Adult (AYA) clinical program to address the unique clinical and psychosocial needs of adolescents and young adults throughout their cancer experience. Patient participants were integral in informing the types of consultation services, including fertility counseling and social work, that would be beneficial in the new AYA clinic. Council members also serve on other advisory boards within this institution, as well as various organizations throughout the country specializing in young adult cancer care. These partnerships have proved vital to introducing local programming in service to the young adult cancer community and to expanding resources to young adults in active treatment and survivorship at this institution.

\section{Implications for Practice}

Each of the councils, developed to support our familycentered care approach, has demonstrated the profound impact of engaging patients and their caregivers in collaborative decision making, not only around individualized treatment plans, but institutional decisions that influence the delivery and context of care for all patients. The pediatric Family Advisory Council set the precedent for patient and caregiver engagement at this institution in 2008 and served as a template for the introduction of an institutional Patient Family Advisory Committee. The CCH Councils continue to provide a platform for all patients and families to be heard throughout all stages of treatment. They provide an exemplar for implementation across diverse pediatric practice settings in their attention to providing context for individuals to collaborate with others from similar treatment experiences (e.g. the Supportive Care Council), as well as those in similar development stages (e.g. impact and YAAC).

Challenges in the implementation process were primarily focused on careful selection of patient and caregiver participants. What emerged as the councils began is the potential for some participants to utilize council engagement as a support or bereavement group. Though a natural desire to share one's experience and seek the feedback of others who have experienced similar circumstances, there were times when it became clear that a particular member may need support outside of the Council structure. This led to challenges in that the needs of one or a few members could become a focal point for the group, deterring from the achievement of larger goals. This raised important questions related to how to vet council members, the need to establish tenure on council, and a thoughtful plan in the event a member may need to leave the group. This resulted in the implementation of physician and advanced practice provider screening of potential council members to determine readiness to participate in the council. In addition, bi-laws have been developed to outline council tenure as well as support for participants who may need to transition off of the council.

The benefits of having a multiple-council structure has proven efficacious in providing unique space for adolescents and young adults to participate, independent of their parents or caregivers. This is particularly evident in an annual meeting of all the councils, where the sharing of initiatives and best practices allows for all of the councils to gain insight into the work of each individual council. While operating independently with distinct goals and directives, the gathering of the councils together promotes alignment of shared goals. In addition, feedback on priority setting is gathered annually to ensure that the councils are guided by collaborative input from patient and provider participants. One example of this was a restructuring of the YAAC. Based on feedback from participants it was determined that working groups within the council would better support the achievement of council goals. The result was four working groups which include: community outreach, education, publishing, and grant writing. These groups focus distinctively on participating in community events to share information about young adult cancer resources, providing education to patients and staff throughout the institution about young adult cancer, creating materials for publication or professional presentation, and raising funds for council initiatives and in support of young adults with cancer, respectively.

Establishing a council or other similar structure that allows for the harnessing of patient and caregiver experiences to inform, consult, involve, collaborate with and empower these individuals to influence healthcare practice and delivery is a hallmark of family-centered care and patient engagement. The Councils provide opportunity for engagement within the microsystem, organizational and even community level to improve healthcare delivery for pediatric, adolescent and young adult patients. ${ }^{20}$ The use of distinct age specific councils, or councils focused on a specific care priority, such as a supportive care, augments the standard PFAC design described in the literature and allows for unique opportunities to engage pediatric and young adult patients and their caregivers in a manner consistent with their psychosocial development and experience. Ultimately these efforts serve to bolster our institutional mission to cure cancer in children and young adults within a caring, life-affirming environment. The patient and caregiver voice is not an ancillary service for the institution, but an integral component to its ability to deliver truly family-centered care..$^{21}$ 


\section{References}

1. Institute for Patient- and Family-Centered Care. Patient- and Family-Centered Care. 2018; http://www.ipfcc.org/about/pfcc.html.

2. Turchi RM, Antonelli RC, Norwood KW, et al. Patient-and family-centered care coordination: A framework for integrating care for children and youth across multiple systems. Pediatrics. 2014;133(5):e1451-e1460.

3. Burns KK, Bellows M, Eigenseher C, Gallivan J. 'Practical'resources to support patient and family engagement in healthcare decisions: a scoping review. BMC health services research. 2014;14(1):175.

4. McGinnis JM, Stuckhardt L, Saunders R, Smith M. Best care at lower cost: the path to continuously learning health care in America. National Academies Press; 2013.

5. International Association for Public Participation. IAP2's Public Participa tion Spectrum. 2014; https://c.ymcdn.com/sites/www.iap2.org/resource /resmgr/foundations_course/IAP2_P2_ Spectrum_FINAL.pdf.

6. Jiang SC, Wan BA, Lam M, Agarwal A, Chow E. A qualitative review of Patient and Family Advisory Councils in cancer care. J Pain Manage. 2017;10(1):59-66.

7. Peikes D, O’Malley A, Wilson C, et al. Early Experiences Engaging Patients Through Patient and Family Advisory Councils. J Ambul Care Manage. 2016;39(4):316-324.

8. Dudley N, Ackerman A, Brown KM et al. Patientand family-centered care of children in the emergency department. Am Acad Pediatrics. 2015; 135(1):e255-e272.

9. Wayman KI. Creating and Sustaining Effective Hospital Family Advisory Councils: Findings from the California Patient and Family Centered Care Network of Pediatric Hospitals. 2015; http://www.lpfch.org/sites/default/files/field/pub lications/creating_and_sustaining_effecti ve_hospital_family_advisory_councils.pdf

10. Cunningham R, Walton MK. Partnering With Patients to Improve Care: The Value of Patient and Family Advisory Councils. J Nurs Admin. 2016;46(11):549-551.

11. Smith J, Swallow V, Coyne I. Involving parents in managing their child's long-term condition-A concept synthesis of family-centered care and partnership-in-care. Journal of Pediatric Nursing: Nursing Care of Children and Families. 2015;30(1):143-159.

12. Luff D, Allair B, Litterer K, et al. Parent and Teen Engagement in Pediatric Health Services Research Training. Academic pediatrics. 2016;16(5):496-498.
13. Smith TJ, Temin S, Alesi ER, et al. American Society of Clinical Oncology provisional clinical opinion: the integration of palliative care into standard oncology care. Journal of clinical oncology. 2012;30(8):880-887.

14. Weaver MS, Heinze KE, Bell CJ, et al. Establishing psychosocial palliative care standards for children and adolescents with cancer and their families: An integrative review. Palliative medicine. 2016;30(3):212-223.

15. Weaver MS, Heinze KE, Kelly KP, et al. Palliative care as a standard of care in pediatric oncology. Pediatric blood \& cancer. 2015;62(S5).

16. Smith AG, Andrews S, Bratton SL, et al. Pediatric palliative care and inpatient hospital costs: a longitudinal cohort study. Pediatrics. 2015;135(4):694-700.

17. Lotz JD, Jox RJ, Borasio GD, Führer M. Pediatric advance care planning from the perspective of health care professionals: a qualitative interview study. Palliative medicine. 2015;29(3):212-222.

18. Banerjee SC, Manna R, Coyle N, et al. Oncology nurses' communication challenges with patients and families: a qualitative study. Nurse education in practice. 2016;16(1):193- 201.

19. Barakat LP, Galtieri LR, Szalda D, Schwartz LA. Assessing the psychosocial needs and program preferences of adolescents and young adults with cancer. Supportive Care in Cancer. 2016;24(2):823832.

20. Cheung CK, Zebrack B. What do adolescents and young adults want from cancer resources? Insights from a Delphi panel of AYA patients. Supportive Care in Cancer. 2017;25(1):119-126.

21. Carman KL, Dardess P, Maurer M, et al. Patient and family engagement: a framework for understanding the elements and developing interventions and policies. Health Affairs. 2013;32(2):223-231 